\title{
The Effects of Food Neophobia and Food Neophilia on Diet and Metabolic Processing
}

\author{
August Capiola, Bryan Raudenbush \\ Department of Psychology, Wheeling Jesuit University, Wheeling, USA. \\ Email: acapiola702@cardinal.wju.edu
}

Received August $2^{\text {nd }}, 2012$; revised September $2^{\text {nd }}, 2012$; accepted September $9^{\text {th }}, 2012$

\begin{abstract}
Past research shows that food neophobics (those individuals reluctant to try novel foods) and food neophilics (those individuals overtly willing to try novel foods) differ in terms of sensory evaluations, psychophysical ratings, stimulus sampling, physiological responses, and genetic predispositions. The present study assessed whether such factors had an effect on participants' dietary consumption and subsequent nutritional adequacy. One hundred and sixteen participants, aged 18 - 76 years, completed a food diary for three days as well as several eating-related questionnaires. Nutritional summaries and questionnaire scores were subjected to a multivariate analysis of covariance (MANCOVA) with participants being sorted into three groups depending on their Food Neophobia Score. These three groups consisted of food neophobics, average individuals, and food neophilics. Groups were found to differ significantly on dietary intake of 20 specific nutritional and caloric items, with food neophobics typically having the lowest intake. Implications support the initial hypothesis of food neophobics having less nutritionally plentiful diets than food neophilics, thus leading food neophobics to have a nutritionally deficient diet. This finding is important since decrease in nutritional intake can result in health related deficiencies.
\end{abstract}

Keywords: Nutrition; Food Neophobia; Dietary Intake

\section{Introduction}

Humans have the opportunity to partake in a plethora of foods comprising many cultures and styles of preparation. Man is able to sustain himself under the most diverse dietary habits of any omnivore. However, humans are not exempt from the predicament that all omnivores experience when it comes to the selection of food they have available known as the "omnivore's dilemma", where the approach towards new foods may provide a source of nutrition or toxicity thus resulting in neophobic behavior [1]. Whether this evolutionary explanation is the reasoning behind omnivorous eating behaviors, some of these organisms, humans included, have shown reluctance to try novel foods, a behavior defined as food neophobia [2].

In humans, the fear of being poisoned when confronted with a new food item from a restaurant or grocery may not elicit the potential fear of death after ingestion. However, past research does show that the presentation of novel foods elicits an aroused physiological response. Food neophobics have significantly increased pulse, Galvanic skin response, and respirations when presented with novel food items as compared with food neophilics, or individuals with an overt willingness to consume novel foods [3]. Other rationale behind food neophobic behavior may be supported by the research related to phenylthiocarbamide (PTC) sensitivity, where said individuals have a gene that allows them to detect the bitter taste of PTC [4]. Research has linked food neophobia to PTC sensitivity and thus a genetic predisposition to detect the bitterness in phenylthiocarbamide. Physiologically, food neophobics, neophilics and the average eater differ in salivary response when presented with food items. When presented with novel food items, familiar food items, or a control situation, neophobics show decreased salivary responses, whereas neophilics show increased salivary responses, regardless of stimuli [5]. Only the average group showed differences in salivary responses dependent of the level of stimuli familiarity and identity. Ratings of novel foods for food neophobics and neophilics also differ, with neophobics' report of pleasantness being lower and report of intensity being higher than neophilic individuals [6]. Collectively, this past research demonstrates a variety of differences between food neophobics and neophilics, from genetic correlates and physiological differences to psychological preferences and attitude towards novel foods.

The focus of the present study relates to the level of nutrition in food neophobics compared with food neo- 
philics and average individuals. Past research has shown neophobics to have an average body weight of 14 pounds less than neophilics or an average group [7]. Such differences in body weight may be due to lower levels of nutritional intake for individuals classified as food neophobic. However, curiosity remains in the specific nutritional deficit(s) in these individuals. Clearly, systematic evaluation of the dietary intake of food neophobics, neophilics, and an average group was needed to test such a hypothesis. Additionally, assessing participant variables related to eating habits and body satisfaction would allow for further characterization as to whether food neophobia could be attributed to some aspect of pathology.

The researcher would assess specific nutrient characters across a sample of participants from dietary logs recorded by the participants to determine food intake for a random three-day period during an assigned week. The researcher hypothesized that neophobics would intake a significantly lesser quantity of nutritional items as indicated by their dietary logs.

\section{Experimental Methods}

\subsection{Participants}

One hundred and sixteen participants (54 males, 48 females, 14 undesignated) ages 18 - 76 [M = 34.8, $\mathrm{S}=14.4]$, were obtained through convenience sampling to participate in this study. Participants were recruited through a variety of locations such as business offices, college classrooms, and industrial garages. Participants varied in education and occupation. Participants who were introductory Psychology students at a small, liberal arts university were awarded course credit upon completion of this study.

\subsection{Materials}

Participants were given a variety of materials to complete for the duration of the study. Each participant was assigned a food diary and instructed to record the food items they consumed for 3 random days as specified by the researcher. Each food diary allowed participants to record the name of the food item, the amount consumed of each food item, a brief description of the food item, and the location where the food item was obtained. Participants were given four separate diary entry pages per day to record food intake, one page each for breakfast, lunch, dinner, and snacks. The researcher, prior to diary assignment, designated the specific days that the participants were to record their food intake. Each diary page indicated the day and meal that the participant should record their food intake.

Upon completing their respective food diaries, parti- cipants were instructed to complete various questionnaires to assess eating attitudes and general satisfaction of body image. The Eating Disorder Inventory (EDI) is a multi-scale assessment of psychological and behavioral traits that are commonly found in individuals diagnosed with eating disorders such as anorexia nervosa and bulimia [8]. The eight subscales within the EDI measure: drive-for-thinness, bulimia, body-dissatisfaction, ineffectiveness, perfectionism, interpersonal-distrust, interoceptive-awareness, and maturity-fears.

The Eating Attitudes Test (EAT) lists 40 eating-related behaviors to which participants respond by indicating how often a particular behavior applies to them [9].

The Eating Habits Questionnaire (EHQ) was developed to measure disordered eating [10]. Participants were asked to answer questions related to disordered eating that are applicable for both males and females. The questionnaire makes three factors for participant responses: weight-and-dieting, restrained-eating-patterns, and eating.

The Food Neophobia Scale (FNS) serves to calculate an individual's level of food neophobia [2]. The FNS consists of ten questions related to attitudes toward food and eating behaviors. Participants respond to questions by using a 7-point scale, with value selections ranging from "strongly agree" to "strongly disagree". The calculation method used to score the FNS was the same as originally described by the original authors [2].

\subsection{Procedure}

Participants for this study were gathered through convenience sampling and began the experiment by signing a consent form. They were then asked to complete a food diary for three random days during a random seven-day period. The participants were also asked to complete questionnaires related to eating habits and body satisfaction. Participants at larger locations (i.e. business offices, classrooms) were instructed to place their dietary logs and questionnaires into a folder for the researcher to collect at their place of work exactly one week after their materials were given to them. Smaller groups of participants were instructed to return their materials to the researcher when they had completed their dietary logs and questionnaires.

\section{Results}

Prior to data analysis, food diary items were entered into a data analysis program called The Food Processor, Version 10.0, (ESHA Nutritional Research), which broke down the data into a nutritional analysis of participants' three-day diet. The data entry into The Food Processor called for the researcher to make certain assumptions related to the food items participants recorded since some 
items could not be found in the processor's databank. Additionally, some participants forgot to record or specify the amount of a food item they consumed. To standardize such anomalies, the researcher went through a series of criteria to identify the food items in question: an exact match of the food item and specified brand in the databank, a match of the food item but with a different brand or place of purchase, the USDA standard, and then a similar USDA standard that matched the described food as closely as possible. If the item or brand could not be found or was totally unique, the USDA standard was referred to. If the participant did not specify the item brand, the USDA standard was referred to. If the food was totally unknown in food type, such as novelty theme park foods, the item was not entered (such occurrences were recorded less than five times). Other strategies for food classification were any salad that was not described as a particular leaf was classified as "bibb lettuce", a USDA standard. All alcohol in unknown alcoholic mixed drinks was classified as "gin", another USDA standard. Water intake was not entered into the processor.

After food items had been entered into The Food Processor, a nutritional summary was recorded and saved for every participant. The summary was then entered into SPSS (Statistical Package for the Social Sciences, Version 19, IBM, Inc.) for further analysis along with the questionnaire data completed by the participants.

Scores on the FNS were used by the researcher to label participants with the lowest third of scores as food neophilics and the highest third of scores as food neophobics. The middle group was identified as the average group. This categorization was used to distinguish groups throughout the analysis. The use of tri-group designation is standard for further analysis of group data [11].

Dietary information was subjected to a Multivariate Analysis of Covariance (MANCOVA) with $\alpha=0.05$. Independent variables for the analysis were food neophobia grouping (Food Neophobic, Average, Food Neophilic), and dependent variables were nutritional and caloric intake values. Participant sex and age were used as covariates. When the data were analyzed for between subjects effects, the three groups were found to differ significantly on dietary intake of 20 specific nutri- tional and caloric items, with food neophobics typically having the lowest intake of specific nutrients and calories overall. Nutrients of interest that were significantly lower in intake for neophobics compared with neophilics and/or the average group can be found in Table 1 . These results confirm the hypothesis that food neophobics consume a lower variety of foods as shown by their significantly lower amount of various nutrients consumed. This lackluster level of nutritional consumption is seen as a sign of decreased nutritional health and may affect food neophobics' overall health.

Factors from disordered eating scales were subjected to between-groups ANOVAs, with Tukey post-hoc contrasts at $\alpha=0.05$. Dependent measures within the EDI subscale did not yield significant findings, leading the researcher to believe that food neophobia is not related to characteristics that are commonly associated with disordered eaters. Scores on the EHQ and the EAT were also not found to significantly differ in food neophobics, neophilics, or the average group further indicating the absence of significant commonality between food neophobics and disordered eaters. A table of displayed means and p-values can be found in Table 2 .

Table 1. Significant nutritional intake differences among food neophobics, food neophilics, and an average group.

\begin{tabular}{|c|c|c|c|c|c|}
\hline Variable & FNS Group & M & SE & $\mathrm{F}$ & P-value \\
\hline \multirow[t]{3}{*}{ gram_weight } & neophilics & 2493.57 & 184.35 & 2.55 & 0.03 \\
\hline & average & 2116.96 & 195.68 & & \\
\hline & neophobics & 1889.68 & 193.25 & & \\
\hline \multirow[t]{3}{*}{ calories } & neophilics & 3083.18 & 286.55 & 2.54 & 0.03 \\
\hline & average & 3013.14 & 304.16 & & \\
\hline & neophobics & 2349.85 & 300.37 & & \\
\hline \multirow[t]{3}{*}{ calories_fat } & neophilics & 1120.49 & 100.30 & 3.07 & 0.01 \\
\hline & average & 885.03 & 106.46 & & \\
\hline & neophobics & 923.91 & 105.14 & & \\
\hline \multirow[t]{3}{*}{ calories_sat_fat } & neophilics & 333.44 & 27.53 & 3.82 & 0.00 \\
\hline & average & 275.30 & 29.22 & & \\
\hline & neophobics & 303.39 & 28.86 & & \\
\hline \multirow[t]{3}{*}{ protein } & neophilics & 96.28 & 6.51 & 4.47 & 0.00 \\
\hline & average & 88.23 & 6.91 & & \\
\hline & neophobics & 83.54 & 6.82 & & \\
\hline
\end{tabular}




\section{Continued}

\begin{tabular}{|c|c|c|c|c|c|}
\hline \multirow[t]{3}{*}{ other_carbohydrates } & neophilics & 173.00 & 17.38 & 2.67 & 0.02 \\
\hline & average & 166.57 & 18.45 & & \\
\hline & neophobics & 149.98 & 18.22 & & \\
\hline \multirow[t]{3}{*}{ fat } & neophilics & 123.76 & 11.18 & 2.93 & 0.01 \\
\hline & average & 98.50 & 11.86 & & \\
\hline & neophobics & 102.30 & 11.72 & & \\
\hline \multirow[t]{3}{*}{ saturated_fat } & neophilics & 37.05 & 3.06 & 3.79 & 0.00 \\
\hline & average & 30.59 & 3.25 & & \\
\hline & neophobics & 33.80 & 3.21 & & \\
\hline \multirow[t]{3}{*}{ mono_fat } & neophilics & 31.21 & 3.90 & 3.74 & 0.02 \\
\hline & average & 21.92 & 4.14 & & \\
\hline & neophobics & 20.35 & 4.09 & & \\
\hline \multirow[t]{3}{*}{ poly_fat } & neophilics & 15.97 & 2.27 & 2.68 & 0.02 \\
\hline & average & 10.23 & 2.40 & & \\
\hline & neophobics & 11.64 & 2.37 & & \\
\hline \multirow[t]{3}{*}{ trans_fatty_acid } & neophilics & 2.30 & 0.57 & 5.04 & 0.00 \\
\hline & average & 1.20 & 0.61 & & \\
\hline & neophobics & 1.45 & 0.60 & & \\
\hline \multirow[t]{3}{*}{ cholesterol } & neophilics & 290.08 & 24.15 & 2.65 & 0.02 \\
\hline & average & 267.09 & 25.63 & & \\
\hline & neophobics & 268.65 & 25.31 & & \\
\hline \multirow[t]{3}{*}{ niacin_equivalents } & neophilics & 31.86 & 2.81 & 2.68 & 0.02 \\
\hline & average & 28.13 & 2.98 & & \\
\hline & neophobics & 26.67 & 2.94 & & \\
\hline \multirow[t]{3}{*}{ pantothenic_acid } & neophilics & 4.28 & 0.35 & 3.13 & 0.01 \\
\hline & average & 3.18 & 0.37 & & \\
\hline & neophobics & 3.63 & 0.36 & & \\
\hline \multirow[t]{3}{*}{ calcium } & neophilics & 994.01 & 93.54 & 2.78 & 0.02 \\
\hline & average & 823.67 & 99.28 & & \\
\hline & neophobics & 867.80 & 98.05 & & \\
\hline \multirow[t]{3}{*}{ magnesium } & neophilics & 248.96 & 20.75 & 3.32 & 0.01 \\
\hline & average & 222.03 & 22.02 & & \\
\hline & neophobics & 184.81 & 21.75 & & \\
\hline \multirow[t]{3}{*}{ phosphorus } & neophilics & 1151.70 & 92.39 & 5.43 & 0.00 \\
\hline & average & 1048.99 & 98.07 & & \\
\hline & neophobics & 1004.45 & 96.84 & & \\
\hline \multirow[t]{3}{*}{ potassium } & neophilics & 2667.85 & 235.80 & 2.85 & 0.01 \\
\hline & average & 2228.00 & 250.30 & & \\
\hline & neophobics & 2251.46 & 247.18 & & \\
\hline \multirow[t]{3}{*}{ selenium } & neophilics & 72.04 & 6.95 & 3.44 & 0.00 \\
\hline & average & 72.27 & 7.38 & & \\
\hline & neophobics & 66.68 & 7.29 & & \\
\hline \multirow[t]{3}{*}{ omega_3_fatty_acid } & neophilics & 1.02 & 0.16 & 2.63 & 0.02 \\
\hline & average & 0.63 & 0.17 & & \\
\hline & neophobics & 1.13 & 0.17 & & \\
\hline
\end{tabular}


Table 2. Factors from disordered eating scales.

\begin{tabular}{|c|c|c|c|c|c|}
\hline Variable & FNS Group & M & SD & $\mathrm{F}$ & P-value \\
\hline \multirow[t]{3}{*}{ drive_thinness } & 1 & 4.84 & 0.85 & 2.50 & 0.09 \\
\hline & 2 & 4.49 & 1.03 & & \\
\hline & 3 & 4.36 & 0.97 & & \\
\hline \multirow[t]{3}{*}{ interoceptive_awareness } & 1 & 5.26 & 0.47 & 1.46 & 0.24 \\
\hline & 2 & 5.21 & 0.57 & & \\
\hline & 3 & 5.05 & 0.60 & & \\
\hline \multirow[t]{3}{*}{ bulimia } & 1 & 5.41 & 0.52 & 0.46 & 0.63 \\
\hline & 2 & 5.36 & 0.46 & & \\
\hline & 3 & 5.30 & 0.58 & & \\
\hline \multirow[t]{3}{*}{ body_satisfaction } & 1 & 4.46 & 0.88 & 2.09 & 0.13 \\
\hline & 2 & 3.90 & 1.36 & & \\
\hline & 3 & 4.09 & 1.26 & & \\
\hline \multirow[t]{3}{*}{ ineffectiveness } & 1 & 5.04 & 0.65 & 1.03 & 0.36 \\
\hline & 2 & 5.10 & 0.62 & & \\
\hline & 3 & 4.87 & 0.82 & & \\
\hline \multirow[t]{3}{*}{ maturity_fears } & 1 & 4.56 & 0.74 & 1.70 & 0.19 \\
\hline & 2 & 4.30 & 0.74 & & \\
\hline & 3 & 4.29 & 0.62 & & \\
\hline \multirow[t]{3}{*}{ perfectionism } & 1 & 3.29 & 1.04 & 1.86 & 0.16 \\
\hline & 2 & 3.71 & 1.04 & & \\
\hline & 3 & 3.33 & 1.05 & & \\
\hline \multirow[t]{3}{*}{ interpersonal_distrust } & 1 & 4.73 & 0.59 & 3.08 & 0.05 \\
\hline & 2 & 4.76 & 0.79 & & \\
\hline & 3 & 4.40 & 0.68 & & \\
\hline \multirow[t]{3}{*}{ EAT } & 1 & 8.54 & 5.01 & 1.14 & 0.32 \\
\hline & 2 & 9.30 & 6.44 & & \\
\hline & 3 & 10.57 & 5.95 & & \\
\hline \multirow[t]{3}{*}{ EHQ } & 1 & 10.16 & 6.11 & 1.93 & 0.15 \\
\hline & 2 & 12.03 & 5.26 & & \\
\hline & 3 & 12.66 & 5.68 & & \\
\hline \multirow[t]{3}{*}{ FNS } & 1 & 21.24 & 0.75 & 248.47 & 0.00 \\
\hline & 2 & 32.47 & 0.77 & & \\
\hline & 3 & 44.86 & 0.76 & & \\
\hline
\end{tabular}

\section{Discussion and Conclusions}

The present study was designed to assess the differences in nutritional intake between food neophobics, food neophilics, and an average group. The researcher hypothesized that food neophobics would have significantly lower levels of intake on a number of nutrient characters that would account for their significantly lower body weights in past research [7].

Referring to the initial hypothesis, food neophobics did in fact intake fewer nutrients when compared to food neophilics and the average eater. Criteria to make such a statement was determined by the 20 specific nutrient characters for which food neophobics ate significantly less than one or both of the other groups.

Mentionable nutritional deficits experienced by the food neophobics include dietary intake of protein, monounsaturated fats, and magnesium. Dietary intake of protein is epecially important for infants and children who require 2 to $2.2 \mathrm{~g}$ of protein per kilogram of body weight 
per day, and individuals who participate in physical work, are menstruating, pregnant or lactating, or are in a state of convalescence who require increased protein intake [12]. Mono-unsaturated fats have been linked in reducing low-density lipoprotein levels without effecting highdensity lipoprotein levels, and this deficiency may lead to higher LDL levels which have been linked in coronary artery disease [12]. Magnesium deficiency can cause tetany similar to calcium deficiency (hypocalcemia), weakness, and mental depression [12].

The nutritional deficits experienced by food neophobics support past research indicating food neophobics have significantly lower body weights [7]. The lower calories consumed by the sample of neophobics overall, as well as the lower levels of consumed calories from fat and specifically saturated fat, help to bolster the validity of such a finding. Evidence for consuming fewer nutrients may also support cephalic response inhibiting perceived appetite [5]. With several nutrients being lower in intake across food neophobics, presence of a physiological difference in reactions to several novel foods containing a variety of nutrients can be viewed as intuitive and the possibility of a genetic difference in these individuals may be viewed as more likely [3,4].

After further assessing the collected data, it is concluded that food neophobia is not a pathological disorder similar to other eating disorders. This conclusion is based on the findings that there were no significant differences among the groups on any of the disordered eating questionnaires (EAT, EDI, EHQ). Instead, food neophobia appears to be more of a personality trait in which individuals simply execute and continue a pattern of unwillingness to try novel foods and continue a nutritionally de- ficient diet as supported by this study.

With the present study resulting in food neophobia being a matter of preference rather than a psychological or personality disorder, interventions for individuals may be a simpler matter than the clinical treatment of eating disorders. Past research suggests that allowing individuals to have experiences with novel foods, and thus removing the novelty, facilitates individuals approaching novel foods [13]. For example, as the number of experiences with fruit juices increased the more participants liked it [14]. However, the amount of time it takes to aquire a preference to a novel food by either food neophilics or food neophobics has yet to be carefully assessed [15]. The result that level of food neophobia may be lowered with exposure to novel foods is not an unwelcomed result for these researchers. With greater ease of lowering food neophobia level, it may require less effort to get food neophobics to engage in healthier dietary practices.

\section{Acknowledgements}

We would like to acknowledge the NASA West Virginia
Space Grant and the Psi Chi/American Psychological Association Summer Research Grant for their generous funding to complete this research.

\section{REFERENCES}

[1] P. Rozin, "The Use of Characteristic Flavorings in Human Culinary Practice,” In: C. M. Apt, Ed, Flavor: Its Chemical, Behavioral and Commercial Aspects, Westview Press, Boulder, 1977.

[2] P. Pliner and K. Hobden, "Development of a Scale to Measure the Trait of Food Neophobia in Humans," Appetite, Vol. 19, No. 2, 1992, pp. 105-120. doi:10.1016/0195-6663(92)90014-W

[3] B. Raudenbush and A. Capiola, "Physiological Responses of Food Neophobics and Food Neophilics to Food and Non-Food Stimuli," Appetite, Vol. 58, No. 3, 2012, pp. 1106-1108. doi:10.1016/j.appet.2012.02.042

[4] E. Carter, V. Donely, C. Sonson, N. Santaniello, M. Stanely and B. Raudenbush, "PTC Sensitivity Differentiates Food Neophobics and Food Neophilics," Proceedings of the Annual Meeting of the Society for the Study of Ingestive Behavior, Dublin, 25-29 July 2000.

[5] B. Raudenbush, N. Corley, N. R. Flower, A. Kozlowski, and B. Meyer, "Cephalic Phase Salivary Response Differences Characterize Level of Food Neophobia,” Appetite, Vol. 41, No. 2, 2003, pp. 211-212.

doi:10.1016/S0195-6663(03)00059-X

[6] H. Tuorila, H. L. Meiselman, R. Bell, A. V. Cardello and W. Johnson, "Role of Sensory and Cognitive Information in the Enhancement of Certainty and Liking for Novel and Familiar Foods," Appetite, Vol. 23, No. 3, 1994, pp. 231-246. doi:10.1006/appe.1994.1056

[7] B. Raudenbush, N. Corley, N. R. Flower, A. Kozlowski and B. Meyer, "Nutritional Intake Differences in Food Neophobics and Neophilics," Proceedings of the Annual Meeting of the Society for the Study of Ingestive Behavior, Philadelphia, 24 July 2001.

[8] D. M. Garner, M. P. Olmstead and J. Polivy, "Development and Validation of a Multidimensional Eating Disorder Inventory for Anorexia Nervosa and Bulimia," International Journal of Eating Disorders, Vol. 2, No. 2, 1983, pp. 15-34.

doi:10.1002/1098-108X(198321)2:2<15::AID-EAT22600 20203>3.0.CO;2-6

[9] D. M. Garner and P. E. Garfinkel, "The Eating Attitudes Test: An Index of the Symptoms of Anorexia Nervosa,” Psychological Medicine, Vol. 9, No. 2, 1979, pp. 273-279. doi:10.1017/S0033291700030762

[10] S. Coker and D. Roger, "The Construction and Preliminary Validation of a Scale for Measuring Eating Disorders,” Journal of Psychosomatic Research, Vol. 34, No. 2, 1990, pp. 223-231. doi:10.1016/0022-3999(90)90056-A

[11] R. A. Frank and B. Raudenbush, "Individual Differences in Approach to Novelty: The Case of Human Food Neophobia,” In: R. R. Hoffman, M. F. Sherrick and J. S. Warm, Eds., Viewing Psychology as a Whole: The Integrative Science of William N. Dember, American Psy- 
chological Association, Washington DC, 1998, pp. 227245. doi:10.1037/10290-010

[12] C. W. Taber and C. L. Thomas, “Taber's Cyclopedic Medical Dictionary,” F. A. Davis, Philadelphia, 1997.

[13] P. Pliner, M. Pelchat and M. Grabski, "Reduction of Food Neophobia in Humans by Exposure to Novel Foods," Appetite, Vol. 20, No. 2, 1993, pp. 111-123.

doi:10.1006/appe.1993.1013
[14] P. Pliner, "The Effect of Mere Exposure on Liking for Edible Substances,” Appetite, Vol. 3, No. 3, 1982, pp. 283290. doi:10.1016/S0195-6663(82)80026-3

[15] B. Raudenbush and R. A. Frank, "Assessing Food Neophobia: The Role of Stimulus Familiarity,” Appetite, Vol. 32, No. 2, 1999, pp. 261-271. doi:10.1006/appe.1999.0229 